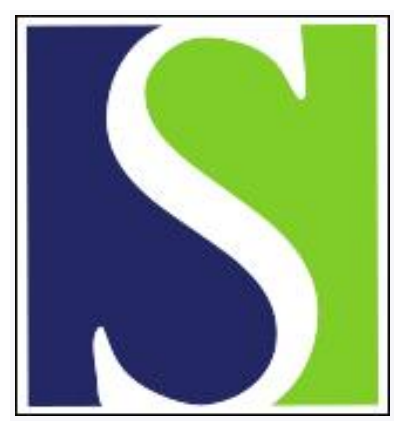

Scand J Work Environ Health 1989;15(2):117-124

https://doi.org/10.5271/sjweh.1873

Issue date: Apr 1989

Occupational noise exposure and course of pregnancy.

by Nurminen T, Kurppa K

Affiliation: Institute of Occupational Health, Department of Epidermiology and Biostatistics, Helsinki, Finland.

The following article refers to this text: 2021;47(1):33-41

This article in PubMed: www.ncbi.nlm.nih.gov/pubmed/2772574

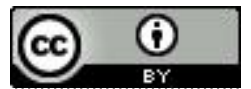




\title{
Occupational noise exposure and course of pregnancy
}

\author{
by Tuula Nurminen, MSc, Kari Kurppa, MD 1
}

\begin{abstract}
NURMINEN T, KURPPA K. Occupational noise exposure and course of pregnancy. Scand J Work Environ Health 1989;15:117-24. The study examined the possible relation of occupational noise exposure to adverse pregnancy outcomes. The experience of 1190 reference mothers from a case-referent study based on the Finnish Register of Congenital Malformations was scrutinized. Exposure to noise was blindly assessed from a description of the mother's workday by two industrial hygienists. Women with an estimated level of noise of around $80 \mathrm{~dB} \mathrm{~L} \mathrm{Leq}_{(8 \mathrm{~h})}$ or higher were considered exposed. Threatened abortion was not associated with noise exposure alone, but, when it was combined with shift work, the adjusted risk was over twofold. The adjusted risk of pregnancy-induced hypertension was twice as high among the mothers exposed to noise in shift work, and the duration of their pregnancy was shorter. The analyses produced indications of a relation between noise and growth retardation which was not connected with shift work. There were significantly ascending trends in the proportions of these outcomes according to increasing exposure intensity.
\end{abstract}

Key terms: birthweight, length of gestation, placental weight, pregnancy-induced hypertension, threatened abortion, vaginal bleeding.

Exposure to environmental aircraft noise has been associated with low birthweight $(1-3)$, reduced length of pregnancy (4), teratogenic risk (5), toxemia of pregnancy (see reference 2), and a decline of human placental lactogen (2). Similar results related to noise have been reported for pregnant laboratory animals, and some possible biological mechanisms have been suggested. (See references 6 and 7.)

Reproductive and obstetrical effects of occupational noise exposure have not been studied to a great extent. In one study, however, an excess of hormonal disturbances, delayed conception, and infertility was reported among female workers exposed to noise (8). McDonald et al (9) reported an association between exposure to noise and spontaneous abortion in their Montreal study, but this relation was not confirmed in their second analysis of the same data. Heidam (10) nominated noise and shift work as possible explanations for the increased risk of spontaneous abortion among Danish factory workers. In a French study noise was an element of a composite score of fatigue which correlated with preterm delivery (11). In the Montreal study noise was associated with low birthweight in the health and manufacturing sectors (12). In a Finnish study occupational noise exposure was not a risk factor of preterm birth or low birthweight, but, as the authors stated, the study had a low power to detect moderate risks (13).

To study the effects of occupational exposure to noise on threatened abortion, pregnancy-induced

\footnotetext{
Institute of Occupational Health, Department of Epidemi-
} ology and Biostatistics, Helsinki, Finland.

Reprint requests to: Ms T Nurminen, Department of Epidemiology and Biostatistics, Institute of Occupational Health, Topeliuksenkatu 41 a A, SF-00250 Helsinki, Finland. hypertension, length of gestation, and birthweight, we have used the information available on the evaluated noise exposures of the reference mothers from a Finnish case-referent study on birth defects and examined the course of the mothers' pregnancies.

\section{Subjects and methods}

Our general approach to studying the effects of exposure to noise during pregnancy has been described in a communication that addressed teratogenic risk (14). The study included 1475 Finnish mothers of infants with structural birth defects and their time- and area-matched reference mothers obtained from the Finnish Register of Congenital Malformations between 1976 and 1982. In the present study of pregnancy outcomes other than malformations we used information on the noncase mothers' experience. This procedure has been described in more detail elsewhere (15).

The mothers were interviewed, according to standard Register practices, about the particulars of their latest and previous pregnancies, consumption of drugs and alcohol, smoking habits, etc (16). We obtained information pertaining to the course and outcome of the pregnancy under study from both the antenatal record of the maternity health care center and the Register questionnaire.

The question of whether the mother had had a threatened abortion during her pregnancy was asked in the Register interview by a midwife. We considered bleeding with or without pain as an indication of a threatened abortion but not lower abdominal pain only. For $73 \%$ of the mothers who had experienced a threatened abortion, the symptoms had occurred in the first trimester. 
An increase of at least $20 \mathrm{~mm} \mathrm{Hg}(3 \mathrm{kPa})$ in the mean arterial blood pressure between the mother's first visit to the maternity health care center and her last visit before delivery was considered to indicate pregnancyinduced hypertension (17). The mean arterial blood pressure was calculated as one-third of the pulse pressure plus the diastolic pressure.

The length of gestation was calculated from the first day of the last normal menstrual period and was expressed in completed days. The birth was considered preterm when the duration of gestation was less than 37 completed weeks, and a prolonged pregnancy was one lasting 42 weeks or longer. For the definition of a small baby for his or her gestational age, we used as a reference value the tenth percentile birthweight of the babies of the same gender born to mothers who were not exposed to noise in the same gestational age group. The applied gestational age groups were $<37$ weeks, 37-39 weeks, $40-41$ weeks, and $\geq 42$ weeks.

The Register data were supplemented with detailed interviews on the mothers' work conditions and various exposures related to occupational or leisure-time activities $(18,19)$. Among the 1475 noncase mothers, there were 270 who had not worked during their pregnancy. We excluded these mothers from the study. Fourteen of the mothers who had worked had twin births, and in the case of one woman information on the number of fetuses was missing; these 15 women were also excluded. Of the remaining mothers, 1044 had worked throughout most of their pregnancy, and 146 had worked only temporarily. Of the latter group $87 \%$ had worked in the first trimester and the rest only later during their pregnancy. The reason for stopping work was the termination of employment for $51 \%$ of these mothers, maternity leave or vacation for $10 \%$, and sick leave or overstrain for $19 \%$; the rest had other reasons or the reason was unknown. When we studied the occurrence of threatened abortion, all the mothers who had worked were part of the analysis. When other aspects were under consideration, we included only mothers who had worked throughout most of their pregnancy.

Exposure to noise was inquired about in a fixed question in the special interview, and additional information was obtained from the description of the mother's workday, which had been recorded in detail. The noise exposures were assessed by two industrial hygienists. (See reference 14.) In all, 429 mothers (36\% of those who had worked during pregnancy) reported exposure to noise. According to the hygienists' assessments 102 mothers $(9 \%$ of those who had worked) had been exposed to an 8-h equivalent continuous A-weighted sound level $\left(\mathrm{L}_{\mathrm{Aeq}(8 \mathrm{~h})}\right)$ of around $80 \mathrm{~dB}$ or higher. Ninety-five $(9 \%)$ of the mothers who had worked throughout most of their pregnancy were assessed as exposed. The exposure of two of these mothers had taken place only in the first trimester, while all of the other mothers had been exposed during their entire pregnancy. Seven $(5 \%)$ of the mothers whose work was temporary were considered exposed, and, of these seven, six had been exposed in the first trimester and one later during pregnancy. The hygienists used preselected exposure categories in their assessment. The selected noise levels were considered to represent ordinally scaled exposure categories of (i) "no" appreciable exposure (clearly less than $\left.80 \mathrm{~dB} \mathrm{~L} \mathrm{~L}_{\mathrm{Aeq}(\mathrm{B})}\right)$, (ii) exposure of "low" intensity (around $80 \mathrm{~dB} \mathrm{~L}_{\mathrm{Aeq}(8 \mathrm{~h})}$ ), (iii) exposure of "moderate" intensity (around $85 \mathrm{~dB} \mathrm{~L}_{\text {Aeq(8 h}}$ ), and (iv) exposure of "high" intensity (around $90 \mathrm{~dB} \mathrm{~L} \mathrm{~L}_{\text {Aeq(8 h) }}$ or higher). According to the hygienists 59 mothers had been exposed to low, 35 to moderate, and 8 to high intensity noise. The reported use of hearing protectors during pregnancy was $15 \%$ among the mothers with low, $60 \%$ among those with moderate, and $87 \%$ among the mothers with high exposure. The category of high exposure intensity was pooled with the moderate group because of insufficient numbers for a separate statistical analysis.

Nearly all $(97 \%)$ of the mothers who were exposed to noise belonged to the socioeconomic category of manual workers (according to reference 20 ), whereas only $26 \%$ of the unexposed belonged to the same category. Moreover, almost $90 \%$ of the exposed mothers were employed in manufacturing and related occupations, and none of them had been in agricultural work. Control of confounding was done by additional analyses in which the subjects were restricted, first, to nonagricultural manual workers and, second, to mothers in manufacturing and related jobs.

The physical strain of the occupational activities of the mothers was evaluated with a standardized method (21) reflecting energy expenditure. When we studied the associations between noise and pregnancy outcomes, we looked at the possible modifying or confounding effects of shift work, physical work load, and exposure to solvents on these relations. For threatened abortion we controlled also for temporariness of employment.

The mothers who were exposed to noise were younger, had experienced more adverse pregnancy outcomes, more often had a low prepregnancy weight, were more often regular smokers, but consumed less alcohol during pregnancy than the unexposed mothers who had worked during pregnancy (table 1). For threatened abortion we considered the possible confounding effects of maternal age, parity, outcome of previous pregnancies, history of menstrual irregularity, intake of drugs, alcohol consumption, and smoking. For pregnancy-induced hypertension we adjusted for maternal age, parity, outcome of previous pregnancies, alcohol intake, and smoking. The models for gestational age included the covariates maternal age, parity, outcome of previous pregnancy, history of menstrual irregularity, alcohol intake, and smoking. When studying the occurrence of babies small for their gestational age, we controlled for maternal age, parity, outcome of previous pregnancies, maternal prepregnan- 
cy weight, alcohol intake, and smoking. In the preliminary scrutiny of the data, other factors, such as mother's residential area and obesity, were also considered, but they were not included in the final analyses.

Estimates and confidence limits were calculated for the risk ratios according to the chi-square function procedure presented by Miettinen \& Nurminen (22). To test for trend in the proportions according to the ordinal level of noise exposure, we used the chi-square statistic of Armitage (23). Power calculations for single $2 \times 2$ tables were carried out with methods derived by Miettinen $(24,25)$ with a significance level of $\alpha=0.025$ and a one-sided test.

We calculated the estimates of the adjusted risk ratios from the results of binomial regression analyses executed with the generalized linear interactive modeling (GLIM) program and the macros written by Wacholder (26). To relate the numeric variable gestational age to noise exposure, we fitted normal linear regression models. The distribution of the outcome variate was very skewed toward shorter gestational age and had a high peak around the modal value. To fulfill the assumption of normality, the outcome variate was subjected to a normal scoring procedure given by Blom (27). The standardized normal scores were calculated, and the linear regression models were fit with the SAS software system $(28,29)$.

\section{Results}

\section{Threatened abortion}

Twelve percent of the 429 mothers who had reported exposure to noise had experienced vaginal bleeding, whereas the corresponding value was $8 \%$ for the 761 mothers not reporting such exposure. The crude risk ratio was 1.4 with a $95 \%$ confidence interval $(95 \%$ CI) of 1.0-2.0. The crude risk ratio for vaginal bleeding in the first trimester was $1.6(95 \%$ CI $1.1-2.5)$ for noise exposure in the first trimester, as reported by the mother.

Fifteen percent of the 102 mothers who were exposed to noise according to the hygienists had suffered from vaginal bleeding during their pregnancy, as against $9 \%$ of the 1088 unexposed mothers. The crude risk ratio was $1.6(95 \%$ CI $1.0-2.6)$. Table 2 shows the proportions of mothers with vaginal bleeding according to the level of exposure intensity. There was a significant trend in the proportions, and the risk ratio for the mothers with moderate or high exposure was $2.0(95 \%$ CI 1.0-3.7) when they were contrasted to the unexposed mothers. The crude risk ratio was $2.2(95 \% \mathrm{CI}$ 1.3-3.6) for noise exposure and threatened abortion in the first trimester.

Upon adjustment for work conditions and maternal background characteristics, the mothers exposed to noise in shift work had an elevated risk of threatened abortion as compared with the mothers unex-
Table 1. Background characteristics of all the employed mothers with and without exposure to noise.

\begin{tabular}{lcc}
\hline Background characteristic & $\begin{array}{c}\text { Exposure } \\
\text { to noise } \\
(\%)\end{array}$ & $\begin{array}{c}\text { No noise } \\
\text { exposure } \\
(\%)\end{array}$ \\
\hline Maternal age 35 years or more & 3.9 & 8.5 \\
$\begin{array}{l}\text { No previous pregnancy } \\
\text { Previous deliveries without }\end{array}$ & 39.2 & 37.7 \\
an adverse pregnancy outcome & 28.4 & 35.6 \\
$\begin{array}{l}\text { Previous adverse } \\
\text { pregnancy outcomeb }\end{array}$ & 32.4 & 26.7 \\
Menstrual irregularity & 10.0 & 9.0 \\
Maternal prepregnancy & & \\
weight less than 50 kg & 15.1 & 10.6 \\
Regular smoking & 21.8 & 10.2 \\
Alcohol intake & 33.0 & 43.1 \\
Intake of drugs & 20.4 & 23.5 \\
\hline
\end{tabular}

a The exposed group included 102 mothers and the unexposed 1088.

b Previous induced abortion, miscarriage, preterm delivery, malformed child, or stillbirth.

Table 2. Threatened abortion and exposure to noise according to the hygienists' assessments.

\begin{tabular}{lrrc}
\hline \multirow{2}{*}{$\begin{array}{l}\text { Exposure } \\
\text { intensity }\end{array}$} & $\begin{array}{c}\text { Number } \\
\text { of mothers }\end{array}$ & \multicolumn{2}{c}{ Vaginal bleeding } \\
\cline { 3 - 4 } & & $\mathrm{N}$ & $\%$ \\
\hline No & 1084 & 99 & 9.1 \\
Low & 59 & 7 & 11.9 \\
Moderate or high & 43 & 8 & 18.6 \\
\hline Trend & & & $X^{2}=4.43$ \\
in proportions & & & $P=0.04$ \\
\hline
\end{tabular}

a There were four mothers in the unexposed group with missing data on symptoms.

Table 3. Adjusted risk ratio estimates and associated $95 \%$ confidence intervals for threatened abortion among all the women with exposure to noise, as assessed by the hygienists, in shift and nonshift work during pregnancy and among the correspondingly exposed nonagricultural manual workers.

\begin{tabular}{lccc}
\hline Work group & $\begin{array}{c}\text { Number of } \\
\text { mothers }\end{array}$ & $\begin{array}{c}\text { Adjusted } \\
\text { risk ratio }\end{array}$ & $\begin{array}{c}95 \% \text { confidence } \\
\text { interval }\end{array}$ \\
\hline $\begin{array}{l}\text { All mothers who } \\
\text { worked during } \\
\text { pregnancy }\end{array}$ & & & \\
$\quad$ Shift work & 198 & $2.1^{\mathrm{a}}$ & $1.0-4.6$ \\
$\quad$ Nonshift work & 988 & $1.0^{\mathrm{b}}$ & $0.5-2.0$ \\
$\begin{array}{l}\text { Nonagricultural } \\
\text { manual workers }\end{array}$ & & & \\
$\quad$ Shift work & 81 & $4.2^{\mathrm{a}}$ & $1.0-18.0$ \\
$\quad$ Nonshift work & 230 & $0.7^{\mathrm{b}}$ & $0.3-2.1$ \\
\hline
\end{tabular}

a The reference category was no noise exposure in shift work

b The reference category was no noise exposure in nonshift work.

posed in shift work (table 3 ). In shift work, the occurrence of vaginal bleeding was $25 \%$ among the exposed mothers who had not used hearing protectors (crude risk ratio $2.9,95 \%$ CI $0.9-7.5$ ), and $27 \%$ among those who had worn hearing protectors (crude risk ratio $3.2,95 \% \mathrm{CI} 1.3-7.0$ ). 
When the analysis was restricted to the socioeconomic category of manual workers and to nonagricultural work, the adjusted risk ratio for noise exposure in shift work was even more elevated (table 3). The occurrence of vaginal bleeding was $30 \%$ ( 8 of 27 women) among the mothers who worked in manufacturing and related occupations and were exposed to noise in shift work, while none (of 6) of the unexposed mothers in shift work in manufacturing jobs had experienced the symptoms.

Table 4. Pregnancy-induced hypertension and exposure to noise in shift and nonshift work, separately according to the intensity of the exposure.

\begin{tabular}{|c|c|c|c|}
\hline \multirow{2}{*}{ Type of work } & \multirow{2}{*}{$\begin{array}{l}\text { Number of } \\
\text { mothers }^{a}\end{array}$} & \multicolumn{2}{|c|}{$\begin{array}{l}\text { Pregnancy-inducec } \\
\text { hypertension }\end{array}$} \\
\hline & & $N$ & $\%$ \\
\hline \multicolumn{4}{|l|}{ Shift } \\
\hline $\begin{array}{l}\text { Any exposure } \\
\text { No exposure } \\
\text { Low intensity of } \\
\text { exposure } \\
\text { Moderate or high } \\
\text { intensity of exposure }\end{array}$ & $\begin{array}{r}29 \\
147 \\
7 \\
\\
22\end{array}$ & $\begin{array}{r}6 \\
10 \\
1\end{array}$ & $\begin{array}{c}20.7^{\mathrm{b}} \\
6.8 \\
14.3 \\
22.7^{\mathrm{c}}\end{array}$ \\
\hline Nonshift & & & \\
\hline $\begin{array}{l}\text { Any exposure } \\
\text { No exposure } \\
\text { Low intensity } \\
\text { of exposure } \\
\text { Moderate or high } \\
\text { intensity of exposure }\end{array}$ & $\begin{array}{r}66 \\
798 \\
50 \\
16\end{array}$ & $\begin{array}{r}6 \\
58 \\
6 \\
-\end{array}$ & $\begin{array}{l}9.1^{d} \\
7.3 \\
12.0 \\
0.0\end{array}$ \\
\hline
\end{tabular}

a There were two mothers in shift work and two mothers in nonshift work with missing data on blood pressure.

b Crude risk ratio 3.0 (95\% confidence interval $1.2-7.3)$.

c Test for trend in proportions: $X^{2}=6.1, P=0.01$.

d Crude risk ratio 1.3 (95\% confidence interval $0.6-2.7$ ).

Table 5. Birthweight by gestational age of the babies born to mothers with and without exposure to noise.

\begin{tabular}{|c|c|c|c|c|}
\hline \multirow[b]{2}{*}{ Gestational age } & \multicolumn{2}{|c|}{ Babies } & \multicolumn{2}{|c|}{ Birthweight (g) } \\
\hline & $\mathrm{Na}^{\mathrm{a}}$ & $\%$ & Median & $\begin{array}{c}\text { Tenth } \\
\text { percentile }\end{array}$ \\
\hline \multicolumn{5}{|l|}{$<37$ weeks } \\
\hline $\begin{array}{l}\text { Mothers exposed } \\
\text { Mothers unexposed }\end{array}$ & $\begin{array}{r}3 \\
24\end{array}$ & $\begin{array}{l}3.2 \\
2.6\end{array}$ & $\begin{array}{l}2230 \\
2605\end{array}$ & $\begin{array}{l}580 \\
980\end{array}$ \\
\hline \multicolumn{5}{|l|}{$37-39$ weeks } \\
\hline $\begin{array}{l}\text { Mothers exposed } \\
\text { Mothers unexposed }\end{array}$ & $\begin{array}{r}37 \\
375\end{array}$ & $\begin{array}{l}39.8 \\
40.1\end{array}$ & $\begin{array}{l}3440 \\
3400\end{array}$ & $\begin{array}{l}2810 \\
2920\end{array}$ \\
\hline \multicolumn{5}{|l|}{$40-41$ weeks } \\
\hline $\begin{array}{l}\text { Mothers exposed } \\
\text { Mothers unexposed }\end{array}$ & $\begin{array}{r}46 \\
471\end{array}$ & $\begin{array}{l}49.5 \\
50.4\end{array}$ & $\begin{array}{l}3510 \\
3670\end{array}$ & $\begin{array}{l}3150 \\
3130\end{array}$ \\
\hline \multicolumn{5}{|l|}{$\geq 42$ weeks } \\
\hline $\begin{array}{l}\text { Mothers exposed } \\
\text { Mothers unexposed }\end{array}$ & $\begin{array}{r}7 \\
64 \\
\end{array}$ & $\begin{array}{l}7.5 \\
6.9 \\
\end{array}$ & $\begin{array}{l}3600 \\
3750 \\
\end{array}$ & $\begin{array}{l}3030 \\
3160 \\
\end{array}$ \\
\hline \multicolumn{5}{|l|}{ Total } \\
\hline $\begin{array}{l}\text { Mothers exposed } \\
\text { Mothers unexposed }\end{array}$ & $\begin{array}{r}93 \\
934\end{array}$ & $\begin{array}{l}100 \\
100\end{array}$ & $\begin{array}{l}3470 \\
3550\end{array}$ & $\begin{array}{l}2900 \\
3000\end{array}$ \\
\hline
\end{tabular}

\section{Pregnancy-induced hypertension}

The mean blood pressure of $10 \%$ of the mothers who reported exposure to noise and $6 \%$ of the mothers who did not increased during pregnancy to a level suggesting pregnancy-induced hypertension (risk ratio 1.6, $95 \% \mathrm{CI} 1.0-2.4)$.

The occurrence of pregnancy-induced hypertension was $13 \%$ for the mothers assessed as exposed by the hygienists and $7 \%$ for those assessed as unexposed (risk ratio $1.8,95 \%$ CI 1.0-3.0). The relation between noise and elevated blood pressure could be seen in the shift work group, in which $23 \%$ of the mothers with exposure of moderate or high intensity had had pregnancy-induced hypertension (table 4). In shift work, $17 \%$ of the exposed mothers who had worked without hearing protectors had experienced pregnancy-induced hypertension (crude risk ratio 2.5, $95 \%$ CI $0.6-8.1$ ), and for the mothers who had used protective equipment the corresponding percentage was 24 (crude risk ratio $3.5,95 \%$ CI $1.2-8.9$ ). When adjustment was made for possible confounding factors, the risk ratio for noise exposure in shift work, as contrasted to noiseless shift work, was $2.5(95 \%$ CI 1.06.6). In the restricted group of nonagricultural manual workers the adjusted risk ratio for noise exposure in shift work was 1.7 (95\% CI 0.5-5.8), and for manufacturing work the corresponding adjusted risk ratio was $2.4(95 \% \mathrm{CI} 0.3-23.1)$.

\section{Length of gestation and birthweight}

The median length of gestation was $281 \mathrm{~d}$ for the mothers who reported noise and $280 \mathrm{~d}$ for those who did not, with interquartile ranges of 12 and $11 \mathrm{~d}$, respectively. The occurrence of preterm birth was $2.3 \%$ in the former group and $2.8 \%$ in the latter. The median birthweight of the babies born to mothers who reported noise exposure was $3520 \mathrm{~g}$, and the tenth percentile birthweight was $2960 \mathrm{~g}$. For the babies of the subjectively unexposed mothers the corresponding birthweights were 3570 and $3000 \mathrm{~g}$, respectively.

The exposed and unexposed mothers, as assessed by the hygienists, had similar proportions of preterm, term, and prolonged pregnancies (table 5), but the power of the study to detect a twofold risk for preterm birth was only $35 \%$. However, the mothers exposed to noise in shift work had a shorter gestation (median $278 \mathrm{~d}$ ) than the unexposed mothers in shift work (median $283 \mathrm{~d}$ ). The adjusted difference in the means of the standardized normal scores of gestational age was -0.34 with a standard error (SE) of 0.21 for any exposure against no exposure to noise in shift work. In the restricted group of nonagricultural manual workers in shift work the corresponding medians were 277 and $284 \mathrm{~d}$, respectively; and the adjusted difference of the normal scores was -0.50 (SE 0.25), indicating a significant deviation. In manufacturing 
Table 6. Occurrence of babies who were small for their gestational age among the mothers in nonshift work with and without exposure to noise in the groups of all mothers who worked throughout most of their pregnancy, nonagricultural manual workers, and mothers in manufacturing and related occupations.

\begin{tabular}{|c|c|c|c|c|c|c|}
\hline \multirow{2}{*}{ Work group } & \multirow{2}{*}{$\begin{array}{l}\text { Total number } \\
\text { of babies }\end{array}$} & \multicolumn{2}{|c|}{$\begin{array}{l}\text { Babies small for } \\
\text { gestational age }\end{array}$} & \multirow{2}{*}{$\begin{array}{l}\text { Crude } \\
\text { risk ratio }\end{array}$} & \multirow{2}{*}{\multicolumn{2}{|c|}{$\begin{array}{l}\text { Adjusted } \\
\text { risk ratio }\end{array}$}} \\
\hline & & N & $\%$ & & & \\
\hline \multicolumn{7}{|c|}{$\begin{array}{l}\text { All mothers who worked throughout } \\
\text { most of their pregnancy }\end{array}$} \\
\hline $\begin{array}{l}\text { Exposed } \\
\text { Unexposed }\end{array}$ & $\begin{array}{r}65 \\
782\end{array}$ & $\begin{array}{r}9 \\
75\end{array}$ & $\begin{array}{r}13.8 \\
9.6\end{array}$ & $1.4 \quad(0.8-2.6)$ & 1.4 & $(0.7-2.8)$ \\
\hline \multicolumn{7}{|c|}{ Nonagricultural manual workers ${ }^{c}$} \\
\hline $\begin{array}{l}\text { Exposed } \\
\text { Unexposed }\end{array}$ & $\begin{array}{r}64 \\
137\end{array}$ & $\begin{array}{l}17 \\
11\end{array}$ & $\begin{array}{r}26.6 \\
8.0\end{array}$ & $3.3 \quad(1.7-6.4)$ & 4.2 & $(2.0-8.7)$ \\
\hline \multicolumn{7}{|c|}{ Manufacturing workers ${ }^{d}$} \\
\hline $\begin{array}{l}\text { Exposed } \\
\text { Nonexposed }\end{array}$ & $\begin{array}{l}58 \\
47\end{array}$ & $\begin{array}{r}17 \\
3\end{array}$ & $\begin{array}{r}29.3 \\
6.4\end{array}$ & $4.6 \quad(1.6-14.2)$ & 4.6 & $(1.3-15.5)$ \\
\hline
\end{tabular}

a $95 \%$ confidence interval in parentheses.

b There was one mother among the exposed and 18 mothers among the unexposed for whom the size for gestational age could not be defined.

c There were four mothers among the unexposed for whom the size for gestational age could not be defined.

d There were two mothers among the exposed and one mother among the unexposed for whom the size for gestational age could not be defined

shift work the median length of gestation was $1 \mathrm{~d}$ shorter for the exposed than for the unexposed.

The median birthweight of the babies born to all exposed mothers was $3470 \mathrm{~g}$, and for the babies of the unexposed mothers it was $3550 \mathrm{~g}$ (table 5). In nonshift work, the crude risk ratio for the exposed mothers giving birth to babies that were small for their gestational age was $1.4(95 \% \mathrm{CI} 0.8-2.6)$ (table 6). Of the exposed mothers in nonshift work who had not used hearing protectors, $12 \%$ had given birth to a small baby (crude risk ratio $1.2,95 \% \mathrm{CI} 0.5-2.5$ ), and this percentage was 23 for the exposed women who had worn protectors (crude risk ratio $2.4,95 \% \mathrm{CI}$ $0.8-5.5$ ). The restriction of the study group to the socioeconomic class of manual workers and to nonagricultural work yielded the crude risk ratio of 3.3 (95\% CI 1.7-6.4) for the possibility of the exposed mothers in nonshift work giving birth to babies small for their gestational age (table 6), and there was a significant trend in the proportions according to exposure intensity (table 7). The relation between noise and small size for gestational age was repeated in the group of manufacturing nonshift workers (tables 6 and 7).

\section{Placental weight}

There were no statistically significant differences between the placental weights of the study groups. The mean placental weight was 596 (SD 119) $\mathrm{g}$ for the mothers who had worked throughout most of their pregnancy and had been exposed to noise according to the hygienists' assessments, and 617 (SD 127) g for the corresponding group of unexposed mothers. In both groups $4 \%$ of the mothers had placentas weighing $400 \mathrm{~g}$ or less.
Table 7. Occurrence of babies who were small for their gestational age according to the intensity of exposure to noise in nonshift work in the groups of all mothers who worked throughout most of their pregnancy, nonagricultural manual workers, and mothers in manufacturing and related occupations.

\begin{tabular}{llc}
\hline Work group & $\begin{array}{c}\text { Total number } \\
\text { of babies }\end{array}$ & $\begin{array}{c}\text { Babies small fo } \\
\text { gestational age }\end{array}$ \\
\cline { 2 - 3 } & $\mathrm{N}$ & $\%$ \\
\hline
\end{tabular}

All mothers who worked

throughout most of their

pregnancy

No exposure

Low intensity of exposure

Moderate or high intensity

of exposure

$\begin{array}{rrr}782 & 75 & 9.6 \\ 49 & 5 & 10.2 \\ 16 & 4 & 25.0\end{array}$

Nonagricultural manual

workers

No exposure

Low intensity of exposure

Moderate or high intensity

of exposure

Manufacturing workers

No exposure

Low intensity of exposure

Moderate or high intensity

of exposure

$137 \quad 11 \quad 8.0$

$\begin{array}{lll}48 & 8 & 16.7\end{array}$

$\begin{array}{lll}16 & 9 & 56.3^{b}\end{array}$

a Test for trend in proportions: $X^{2}=2.6, P=0.11$

Test for trend in proportions: $X^{2}=22.8, P<0.001$

Test for trend in proportions: $X^{2}=21.1, P<0.001$

\section{Discussion}

In our study, exposure to noise of a level of around $80 \mathrm{~dB} \mathrm{~L}_{\text {Aeq(8 h) }}$ or higher appeared only at work. The hygienists did not consider any of the unemployed mothers who reported noise exposure as exposed. Furthermore, most of the exposures had taken place in manufacturing and related work, and the exposed mothers belonged to the socioeconomic category of manual workers. Our concern was to choose noiseless work that would be otherwise comparable to noisy work in terms of potential risk factors of unfavorable 
pregnancy outcomes. This requirement of comparability of effects led us to analyses in which the reference to noisy work was a subdomain of nonexposure. (See reference 30, p 30.) Besides, noisy work could be selective. Through the restrictions we also aimed at contrasts in which, in the absence of the exposure, the compared mothers could be expected to have similar pregnancy outcomes after control for the possible confounders in the analyses. (See reference 30, p 31.)

First, we restricted our study to mothers who had worked during pregnancy. In addition to the broadest reference category of noiseless work in all occupations, we referred to noiseless nonagricultural work when the mothers belonged to the socioeconomic category of manual workers. The largest groups excluded from this comparison were clerical workers in offices and mothers in nursing and health care occupations. After this restriction over $60 \%$ of the unexposed mothers were engaged in service work, mainly in housekeeping and cleaning jobs, and some $30 \%$ did manufacturing and related work. On the other hand, almost $90 \%$ of the exposed mothers were in manufacturing jobs, and the rest did service work. Thus it seemed that the most valid contrast would have been that between noisy and noiseless work in manufacturing occupations. However, our study population was limited so that, in the sharpest contrast, the unexposed reference group became very small and was not ideal in terms of the efficiency of the statistical evaluation.

Because it has been suggested (31) that for the indication of human stress the perception of noise would be more important than the actual noise intensity, we analyzed also subjectively reported noise. Mothers in all socioeconomic categories and in all major occupational groups reported exposure to noise. The best reference for this exposure seemed to be all subjectively noiseless work.

The risk of threatened abortion was slightly elevated among the mothers who reported exposure to noise in response to the fixed question in the questionnaire, and the group that was assessed as exposed by the hygienists had similarly experienced more symptoms. In addition, there was an ascending trend in the risks according to increasing intensity of exposure. When work conditions were taken into account, it was revealed that, in our data, threatened abortion was related to noise only in shift work. The mothers in shift work had an evidently elevated risk when exposed to noise clearly over the level of $80 \mathrm{~dB} \mathrm{~L}_{\mathrm{Aeq}(8 \mathrm{~h}) \text {. The }}$ restricted analyses also suggested an elevated risk of threatened abortion involved in exposure to noise in shift work.

The proportion of women with changes in blood pressure suggesting pregnancy-induced hypertension was slightly higher among the mothers who reported exposure to noise, and it was clearly higher among the mothers who were exposed to noise in shift work, as judged by the hygienists, than among the corresponding unexposed groups. There was a trend in the propor- tions according to exposure intensity. In addition, the restricted analyses yielded elevated risks in shift work. However, in nonshift work, our data showed no relation between noise and pregnancy-induced hypertension.

The Finnish Maternity Act grants a benefit to mothers visiting the maternity center before the end of the fourth month of pregnancy. The typical time of the first visit is around the 12th week of pregnancy; over one-half of the mothers usually register before the end of the first trimester and most before the 20 th week of pregnancy (16). Thus there was variability in the time of the first blood pressure measurements, but a connection with noise exposure that could have biased the observed results does not seem plausible because of the comprehensive maternity care system.

In the aggregate, the duration of pregnancy did not differ between the mothers exposed to noise and those unexposed, and this result applied to both subjectively and objectively assessed exposures. However, in shift work the mothers exposed to noise had a shorter gestation than the unexposed.

The birthweights of the babies born to mothers who reported exposure to noise and those who did not were similar. However, the mothers who were assessed as exposed by the hygienists had more infants that were small for their gestational age when their babies' birthweights were compared with the birthweights of the babies born to the unexposed mothers. The slight excess of small babies was not statistically significant when noisy work was compared with all noiseless work, but in the restricted comparisons the exposed mothers had statistically significantly more small babies. This relation was not connected with shift work, like the previous ones, and the association could be seen among mothers in nonshift work.

The use of hearing protectors did not seem to safeguard against the untoward phenomena under study. The wearing of protective equipment was clearly related to the level of noise and, perhaps also, to the mother's perception of noise. On the other hand, we did not know if the mothers had used protectors all the time while at work.

The exposed group in shift work included relatively more mothers with a moderate or high exposure level. However, this finding did not explain the modifying effect of shift work on the relation of noise to threatened abortion or pregnancy-induced hypertension, because mothers exposed to moderate or high levels of noise also belonged to the exposed group in nonshift work. (See table 4.) Neither could exposure to impulse noise explain the modification because there were only four mothers in shift work and two mothers in nonshift work who had been exposed to this type of noise. There were no remarkable differences in the physical strain of the occupational activities of the mothers exposed to noise and those unexposed, but noise exposure correlated positively with exposure to 
solvents. The obtained results concerning noise were not altered when we controlled for these possible confounders.

The background characteristics differed between the mothers who were exposed to noise and those who were not. (See table 1.) These factors were allowed for in the analyses and, in the restricted comparisons, the mothers were more similar. Still, as always in a nonexperimental study, there remained the possibility that the findings were attributable to some unrecognized confounders.

Maternal memory bias is a possibility when information is acquired retrospectively. The exposure interviews in our study were done after the delivery. However, the actual assessment of noise exposure was done by industrial hygienists, and results of noise measurements at the mother's workplace, or at comparable workplaces, were available in almost all cases. (See reference 14.) Therefore the presence of this bias was unlikely.

Thus, in our data, threatened abortion and pregnancy-induced hypertension were not related to noise alone, but, with the additional strain caused by shift work, the mothers exposed to noise had elevated risks of these outcomes and, also, a shorter gestation. Moreover, our results indicated a relation between noise and reduced prenatal growth. Whether these findings represent true biological effects or were introduced by undetected factors should be examined in future studies.

\section{Acknowledgments}

We thank PC Holmberg, MD, the initiator of the primary case-referent study, K Rantala, $\mathrm{MSc}$ (Chem Eng), and J Starck, PhD, for assessing the noise exposure, Ms T Suomela and Ms R Vesanto-Paavola for their skillful technical assistance, and the Finnish Work Environment Fund for its financial support.

\section{References}

1. Ando $Y$, Hattori H. Statistical studies on the effects of intense noise during human fetal life. J Sound Vib 1973;27:101-10.

2. Ando $\mathrm{Y}$, Hattori $\mathrm{H}$. Effects of noise on human placental lactogen (HPL) levels in maternal plasma. $\mathrm{Br} \mathrm{J} \mathrm{Ob-}$ stet Gynaecol 1977;84:115-8.

3. Knipschild P, Meijer H, Sallé H. Aircraft noise and birth weight. Int Arch Occup Environ Health 1981;48:131-6.

4. Schell LM. Environmental noise and human prenatal growth. Am J Phys Anthropol 1981;56:63-70.

5. Jones FN, Tauscher J. Residence under an airport landing pattern as a factor in teratism. Arch Environ Health 1978;33:10-2.

6. Fanghänel J, Schumacher G-H. Environmental effects on normogenesis and teratogenesis, with special regard to noise and vibration. In: Persaud TVN, ed. Advances in the study of birth defects; vol 2 (Teratological testing). Lancaster (England): MTP Press Ltd, 1979:32552 .

7. Cook RO, Nawrot PS, Hann CW. Effects of high-fre- quency noise on prenatal development and maternal plasma and uterine catecholamine concentrations in the CD-1 mouse. Toxicol Appl Pharmacol 1982;66:338-48.

8. Rachootin P, Olsen J. The risk of infertility and delayed conception associated with exposures in the Danish workplace. J Occup Med 1983;25:394-402.

9. McDonald AD, Armstrong B, Cherry NM, et al. Spontaneous abortion and occupation. J Occup Med 1986; 28:1232-8.

10. Heidam LZ. Spontaneous abortions among dental assistants, factory workers, painters, and gardening workers: a follow up study. J Epidemiol Community Health 1984;38:149-55.

11. Mamelle N, Laumon B, Lazar P. Prematurity and occupational activity during pregnancy. Am J Epidemiol 1984;119:309-22.

12. McDonald AD, McDonald JC, Armstrong B, Cherry $\mathrm{NM}$, Nolin AD, Robert D. Prematurity and work in pregnancy. $\mathrm{Br} \mathrm{J}$ Ind Med 1988;45:56-62.

13. Hartikainen-Sorri AL, Sorri M, Anttonen HP, Tuimala R, Läärä E. Occupational noise exposure during pregnancy: a case control study. Int Arch Occup Environ Health 1988;60:279-83.

14. Kurppa K, Rantala K, Nurminen T, Holmberg PC, Starck J. Noise exposure during pregnancy and selected structural malformations in infants. Scand J Work Environ Health 1989;15:111-6.

15. Nurminen T, Kurppa K. Office employment, work with video display terminals, and course of pregnancy: reference mothers' experience from a Finnish case-referent study of birth defects. Scand J Work Environ Health $1988 ; 14: 293-8$.

16. Saxén L. Twenty years of study of the etiology of congenital malformations in Finland. In: Kalter H, ed. Issues and reviews in teratology; vol 1 . New York, New York: Plenum Publishing Corporation, 1983:73-110.

17. Anderson GD, Sibai BM. Hypertension in pregnancy. In: Gabbe SG, Niebyl JR, Simpson JL, ed. Obstetrics: normal and problem pregnancies. New York, New York: Churchill Livingstone Inc, 1986:819-63.

18. Holmberg PC, Nurminen M. Congenital defects of the central nervous system and occupational factors during pregnancy: a case-referent study. Am J Ind Med 1980; 1:167-76.

19. Kurppa K, Holmberg PC, Hernberg S, Rantala K, Riala $R$, Nurminen $T$. Screening for occupational exposures and congenital malformations: preliminary results from a nationwide case-referent study. Scand J Work Environ Health 1983:9:89-93.

20. Central Statistical Office of Finland. Classification of occupations 1980. Helsinki: Central Statistical Office of Finland, 1981. (Handbook no 14.)

21. Edholm OG. The assessment of habitual activity. In: Evang K, Lange Andersen K, ed. Physical activity in health and disease. Oslo: Universitetsforlaget, 1966: $187-97$.

22. Miettinen $\mathrm{O}$, Nurminen M. Comparative analysis of two rates. Stat Med 1985;4:213-26.

23. Armitage $\mathbf{P}$. Tests for linear trends in proportions and frequencies. Biometrics 1955;11:375-86.

24. Miettinen OS. Individual matching with multiple controls in the case of all or none responses. Biometrics $1969 ; 25: 339-54$.

25. Rothman KJ, Boice JD Jr. Epidemiologic analysis with a programmable calculator. Boston, Massachusetts: Epidemiology Resources Inc, 1982.

26. Wacholder S. Binomial regression in GLIM: estimating risk ratios and risk differences. Am J Epidemiol 1986; 123:174-84.

27. Blom G. Statistical estimates and transformed beta variables. New York, New York: John Wiley \& Sons, 1958.

28. SAS Institute Inc. SAS procedures guide for personal computers. 6th ed. Cary, North Carolina: SAS Institute Inc, 1985. 
29. SAS Institute Inc. SAS/STAT guide for personal computers. 6th ed. Cary, North Carolina: SAS Institute Inc, 1987.

30. Miettinen OS. Theoretical epidemiology. New York, New York: John Wiley \& Sons, 1985.

31. van Dijk FJH, Souman AM, de Vries FF. Non-audito- ry effects of noise in industry: VI. a final field study in industry. Arch Occup Environ Health 1987;59: $133-45$.

Received for publication: 18 November 1988 